J. Lake Sci. (湖泊科学), 2015, 27(4): 700-710

DOI 10.18307/2015.0419

(C) 2015 by Journal of Lake Sciences

\title{
长江倒灌对鄱阳湖水动力特征影响的数值模拟
}

\author{
唐昌新 ${ }^{1}$, 熊 雄 $^{1}$, 邬年华 ${ }^{2}$, 张晓航 ${ }^{3 * *}$, 邹文楠 ${ }^{1 * *}$ \\ ( 1 : 南昌大学工程力学研究所 \高等研究院,南昌 330031) \\ $(2$ : 江西省水利科学研究院, 南昌 332029$)$ \\ (3: 南昌工程学院理学院, 南昌 330099)
}

\begin{abstract}
摘 要: 长江水倒灌是鄱阳湖的一个重要现象, 是江湖作用的具体体现. 利用环境流体动力学开源代码 (EFDC) 建立鄱阳 湖的二维水动力模型, 并借助染色剂模块和水龄模块, 分析鄱阳湖全年的水动力变化过程、倒灌现象及其影响. 数值模拟 结果精确地验证倒灌的发生、持续时间和倒灌流量, 显示倒灌时期湖区水力梯度、湖流逆向的特点. 顶托作用强于翻阳湖 盆地作用时是倒灌发生的条件,通过计算倒灌发生的临界流量并与实际来流进行对比,本文提出新的倒灌判定条件,可 以准确地预测倒灌和预估倒灌流量,且利用 2007-2009 年的测量数据验证了其可靠性. 通过在贑江人流设置染色剂的方 法,模拟获得 2008 年 4 次倒灌人流水体在湖区的占据面积. 顶托作用和倒灌造成湖水不能外泄甚至逆流,增加湖区水体 的水龄,通过数值模拟并与水力停留时间进行对比,估算出湖湖水水龄的增加时间.
\end{abstract}

关键词: 鄱阳湖;长江倒灌;水动力分析;EFDC;水龄

\section{Simulation of the impact of the reverse flow from Yangtze River on the hydrodynamic process of Lake Poyang}

\author{
TANG Changxin $^{1}$, XIONG Xiong ${ }^{1}$, WU Nianhua ${ }^{2}$, ZHANG Xiaohang ${ }^{3}$ \& ZOU Wennan ${ }^{1}$ \\ (1: Institute of Engineering Mechanics/Institute for Advanced Study, Nanchang University, Nanchang 330031, P. R. China) \\ (2: Jiangxi Provincial Institute of Water Sciences, Nanchang 330029, P. R. China) \\ (3: School of Science, Nanchang Institute of Technology, Nanchang 330099, P. R. China)
}

\begin{abstract}
The reverse flow from the Yangtze River is an important phenomenon of the Lake Poyang, embodying the interaction between river and lake. In this paper, a 2D model of the Lake Poyang based on the Environmental Fluid Dynamics Code( EFDC) is established to study the hydrodynamic process, and the reverse flow from the Yangtze River is investigated in favor of the dye module and water age module. The reverse flow appears when the blocking effect of the Yangtze River becomes stronger than the basin effect of Lake Poyang. By calculating the critical flux of the reverse flow and contrasting it with the observed inflow, we propose a new discriminated condition for the reverse phenomenon, which can accurately predict the occurrence and estimate the flux of reverse flow, as validated by the observed data of three years from 2007 to 2009. Using this method to set colouring agent at the inflow of the Ganjiang River, the occupying areas from the Yangtze River are obtained by the simulation of 2008. The blocking effect and the reverse flow of Yangtze River are found to enlarge the water age by preventing the outflow of water from the lake, and the increased time can be estimated by comparing the simulated water age with hydraulic retention time.
\end{abstract}

Keywords: Lake Poyang; reverse flow from Yangtze River; hydrodynamic simulation; EFDC; water age

鄱阳湖 $\left(28^{\circ} 24^{\prime} \sim 29^{\circ} 46^{\prime} \mathrm{N}, 115^{\circ} 49^{\prime} \sim 116^{\circ} 46^{\prime} \mathrm{E}\right)$ 是我国最大的淡水湖泊, 位于长江中下游南岸、江西省北部, 上 承赣江、抚河、信江、修河、饶河 (以下简称“五河”),下接长江,流域面积为 $162225 \mathrm{~km}^{2}$,其中 $156743 \mathrm{~km}^{2}$ 位于 江西省境内,占全流域的 $96.6 \%$,占江西省国土面积的 $93.9 \%$. 鄱阳湖流域东、南、西三面环山,北面临江,中

* 水利部行业专项项目 (201001056) 资助. 2014-03-28 收稿;2014-12-18 收修改稿. 唐昌新(1986 ), 男, 博士研 究生;E-mail:270511737@qq. com.

** 通信作者;E-mail:zhangxh@ nit. edu.cn;E-mail:zouwn@ ncu.edu. cn. 
间河湖交织, “五河” 水系发源于边缘山地,均汇流于鄱阳湖, 然后注人长江, 其水域的成因主要是 “五河” 来 水与下泄长江的水量吞吐动态平衡的结果. 鄱阳湖湖盘自西向东、由南向北倾斜, 高程由湖区 $12 \mathrm{~m}$ 降至湖 口约 $1 \mathrm{~m}^{[1]}$. 鄱阳湖是吞吐型、季节性淡水湖泊,洪、枯水期的湖泊面积、容积相差极大, 高水湖相、低水河相.

鄱阳湖作为长江中下游最大的通江湖泊, 与长江之间存在着复杂的水文和水动力交互作用, 而江水倒 灌是长江顶托过程的极端现象, 是江湖相互作用关系的一种最强烈表现,在一定时期决定性地影响着鄱阳 湖独特的水量和水位波动 ${ }^{[2]}$. 每年 4 月起, 鄱阳湖进人汛期, 流域上游人湖水量增加, 湖区水位升高, 在 7 月 以前, 长江水位不高, 湖水能顺利流出湖口进人长江, 到每年的 7-9 月, 即长江大汛期间, 长江水位升高, 当 湖区水位仍高于湖口长江水位时, 形成顶托作用, 而当湖口长江水位高于湖区水位时, 就会形成倒灌作用. 当长江大汛期间出现洪水时, 通过长江水的倒灌, 鄱阳湖具有蓄洪的作用, 有效地缓解长江下游的洪水情 况. 同时, 长江的顶托和倒灌作用也会阻碍鄱阳湖的排水和排沙, 改变湖区水量、泥沙的平衡, 从而影响湖区 的水资源配置, 对鄱阳湖湿地生态系统的健康和日常生产带来一系列影响 ${ }^{[3]}$.

在“五河”上游、鄱阳湖湖区、长江上游已建和在建的水利工程对倒灌发生的时间和效果都会带来影响, 如三峡水库运行会在 5-6 月增加泄量、10 月减少泄量, 将直接对鄱阳湖产生重大影响 ${ }^{[4]}$. 王鹏等 ${ }^{[5]}$ 利用 EFDC 软件模拟了鄱阳湖水利枢纽工程在预期调度方案下运行后对主湖区及湿地保护区水位的影响. 郭华 等 ${ }^{[6]}$ 通过研究近 50 年来长江与鄱阳湖水文相互作用的变化, 揭示了长江与鄱阳湖的相互作用强度是此消彼 长的关系, 三峡水库的蓄水或放水在一定程度上影响江湖作用的季节变化和鄱阳湖流域的旱涝机率. 方春明 等 ${ }^{[7]}$ 的研究结果表明三峡水库运行 30 年后,由于河道冲刷、鄱阳湖可补水量减少等因素的共同作用,三峡水 库蓄水期的湖口水位下降 $2 \mathrm{~m}$ 左右,这相当于使鄱阳湖的枯水季节提前 1 个月左右. 另外,胡春宏等 ${ }^{[8]}$ 在研究 中提到,在“调枯不调洪”的方案下,鄱阳湖水利枢纽工程建成后,每年仍有一半时间江湖阻隔,改变了江湖自 然连通之态势,引起江湖水情新的变化,而江湖关系究竟发生怎样的变化仍需要开展深人的研究.

闵寒 ${ }^{[9]}$ 从水文、统计的角度分析 $1990 \mathrm{~s}$ 这 10 年间的洪水特征, 总结得出: 鄱阳湖洪水量级大小与持续时 间长短主要由长江中游洪水大小和高水位维持时间长短所决定. $\mathrm{Hu}$ 等 ${ }^{[10]}$ 的研究首先给出长江对鄱阳湖具 有较强顶托作用的判别条件,然后统计历年来顶托作用的强度,得出 1960-2003 年间顶托作用呈现逐渐变 弱的趋势. 胡春华 ${ }^{[11]}$ 通过对在湖口钻孔得到的地质资料进行分析, 确定了在 $2360 \mathrm{a}$ 前首次发生江水倒灌鄱 阳湖盆地, 并利用磁化率作为江水倒灌强度的指标, 得到倒灌强度的变迁, 结果同样显示最近 70 年来倒灌 强度逐渐变弱. 综上所述, 目前相关的研究 ${ }^{[2,6-11]}$ 在较长时间尺度上分析顶托作用的强度变化和倒灌现象, 对 鄱阳湖水动力过程的作用和影响, 以及相关已建和计划建设的大型水利工程将会对以后江湖作用的影响, 所用方法基本是统计分析和数值模拟等.

关于倒灌的数值模拟有效性验证分析、产生倒灌判别条件及倒灌流量的预测、倒灌水体的占据面积大 小、顶托及倒灌对湖体水龄的影响等问题, 目前尚没有具体和详细的研究分析. 与上述问题密切相关的研究 及结论主要有: $\mathrm{Li}$ 等 ${ }^{[12]}$ 利用 MIKE 21 的模拟结果显示, 湖口流量的数值模拟能较好地拟合实测结果. 谢波 等 ${ }^{[13]}$ 对走航式 ADCP 法与常规流速仪法在鄱阳湖湖口 2004 年 2 月 26 日至 10 月 29 日期间的泄量进行比 测, 结果显示在小流量和倒灌期负流量情况下, 相对误差较大, 这是由于倒灌期顺逆不定等原因造成的. 方 春明等 ${ }^{[7]}$ 分析表明: (1) 湖口水位与长江干流流量相关性较好, 而与湖口流量之间只是部分相关, 且关系散 乱; (2) 湖口出现倒灌的简化判别条件为,长江九江站流量日涨幅超过鄱阳湖湖口前一天的流量.

本文利用环境流体动力学开源代码 ${ }^{[14-15]}$ (Environmental Fluid Dynamics Code,EFDC, 其已被用于 80 多个 案例的模拟研究,包括对美国及其他国家的河流、湖泊、河口、海湾和湿地等的研究 ${ }^{[15]}$ ) 的水动力模块模拟 得到鄱阳湖的水位和流程信息,分析鄱阳湖 2008 年的水动力演化过程,验证了倒灌现象,并基于湖口水位 和“五河” 来流, 建立新的产生倒灌的判别条件, 并通过 2007-2009 年的数据验证该方法的可靠性. 同时, 以 染色剂作为示踪剂, 观察倒灌时期湖流方向, 分析倒灌水体的占据面积和区域. 顶托作用和倒灌使湖水不能 外泄,降低湖体水体交换能力和输运能力,基于 EFDC 水龄模块分析其对鄱阳湖水龄的影响.

\section{1 方法}

\section{1 数学模型}

水动力的数值模拟最早是海岸工程和水运工程中重要的模拟方法, 随着近代电子计算机和数值计算方 
法的发展而不断发展, 现在已经是研究和分析湖泊水体污染的常用方法. 本文使用的 EFDC 模型, 最早是由 美国弗吉尼亚州海洋研究所 Hamrick 教授等集成多个数学模型开发研制的综合模型,集水动力模块、泥沙输 运模块、污染物运移模块和水质预测模块为一体, 具有灵活的变边界处理技术和通用的文件输人格式. 另 外, EFDC 还具有如下优点: (1) 开发有完整的前、后处理软件 EFDC-Explorer, 采用可视化的界面操作, 能快 速生成网格数据和处理图像文件 ${ }^{[16]}$; (2) 平面采用曲线正交坐标系, 垂向采用 $\sigma$ 坐标, 能较好地拟合近岸复 杂的岸线和地形; (3) 具有各种流量边界、压力/开放边界、水利结构边界选择, 能充分满足实际情况的需 求. 该模型基于笛卡尔正交曲线和垂直 $\sigma$ 坐标系统的有限差分方法对水动力控制方程进行求解 ${ }^{[13]}$. 本文在 相关人湖河流人口处连续释放染色剂, 示踪湖流流向. 染色剂是假设以溶解态存在、同时不会发生吸附作用 的物质. 水龄定义为颗粒物从人口传输到指定点的时间, 即空间某点的水龄表示水体从开始进人关注区域 到该点所需的时间 ${ }^{[17]}$. 对于水团水龄的定义, 由于水的扩散和混合过程, 水团中的水质点将和周围的环境不 断交换, 进人水团的水质点与原有的水质点有着不同的水龄, 所以 Deleersnijder 等假定水龄满足质量加权平 均, 即水团的平均水龄等于各质点水龄的质量加权的代数平均, 详细计算过程参考文献 [18].

\section{2 模型建立}

模拟区域为整个鄱阳湖湖域 (图 1a), 面积为 $3143 \mathrm{~km}^{2}$. 用 Delft RGFGrid 划分鄱阳湖曲线正交四边形网 格 (图 1b), 总计 78477 个网格, 网格边长的变化范围为 $57 \sim 407 \mathrm{~m}$, 平均网格边长为 $173 \mathrm{~m}$, 同时为更好地刻 画北部人江水道地形, 对该区域网格划分相对更加细密. 本文采用 1998 年的边界和地形数据, 由江西省水 利科学研究院提供, 地形数据分辨率为 215774 个点, 平均点距为 $120 \mathrm{~m}$, 结合圩堤数据, 确定最终的鄱阳湖 边界. 选择采用靠近鄱阳湖南昌站的气象数据.

鄱阳湖的人流主要是 “五河”, 分为多条支流进人鄱阳湖, 以流量边界条件, 给定流量时间序列的方式设 定 (图 1b). 各人湖处流量的测量站点有: 修水为虬津和万家埠, 赣江为外洲, 抚河为李家渡, 信江为梅港, 乐 安河为虎山, 昌江为渡峰坑. 水文站以下积水面积产生的人湖流量, 利用平均降雨 $\times$ 降雨径流系数得到 ${ }^{[19]}$. 鄱阳湖出流是通过湖口进人长江的, 以开边界、给定水位时间序列的方式设定 (图 1b). “五河” 中以赣江流 量最大 (赣江 2008 年流人鄱阳湖的水量占总水量的 $55 \%$ ), 因此本文以赣江为例, 对赣江人流水体进行染色

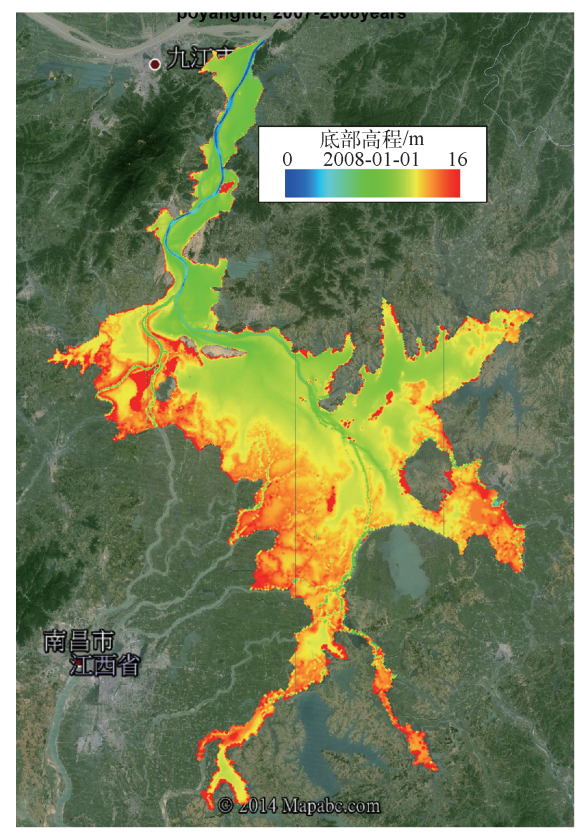

a. 底床地形

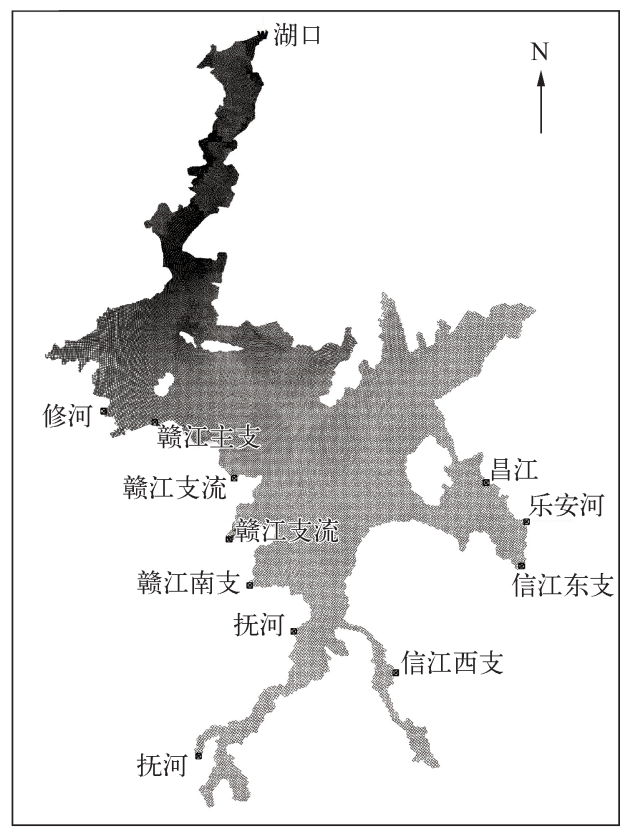

b. 平面网格和边界条件

图 1 鄱阳湖模型

Fig. 1 Lake Poyang model 
标记. 关于染色剂, 模型中设置不发生衰减, 即其衰减速率为 $0 \mathrm{~d}^{-1}$. 赣江分 4 条支流人湖, 在支流人口处设置 包含单位浓度 $1 \mathrm{mg} / \mathrm{L}$ 的染色剂, 其他河流的人口处没有染色剂, 即设为 $0 \mathrm{mg} / \mathrm{L}$ 的染色剂.

\section{3 模型率定}

模型率定是指通过理论和经验建立的初始水动力分析模型, 当涉及诸多难以测量标定或不确定的参数 时只能预先假设, 但需要将基于假设参数的模拟结果与真实测量的典型水力参数数据进行对比率定, 只有 当率定的误差在可接受范围时,才可以确定模拟结果作为后续分析的基础 ${ }^{[16]}$. 选取 2007 年 3 月 1 日至 12 月 31 日为率定期 (表 1 、图 2), 确定模型相关参数. 在水动力模型中, 经常需要调整的参数是底部粗䊅度 (一 般默认取值 $0.02 \mathrm{~m}$ ), 其值的变化依赖于泥沙粒径和植被类型, 经过多次试算,在湖区多水生植物区域设为 $0.05 \mathrm{~m}$, 多泥沙区域设为 $0.01 \mathrm{~m}$. 为保证本模型运行的稳定性,选择湿网格临界水深为 $0.08 \mathrm{~m}$,干网格水深 为 $0.07 \mathrm{~m}$, 运行时间步长为 $5 \mathrm{~s}$.

\section{表 1 水位和湖口水文站泄量模拟误差分析}

Tab. 1 Error analysis of simulation about water levels and outflow discharge at Hukou gauging station

\begin{tabular}{|c|c|c|c|c|c|c|c|c|}
\hline \multirow[b]{2}{*}{ 站点项目 } & \multicolumn{4}{|c|}{ 率定期 (2007 年 3 月 1 日- 12 月 31 日) } & \multicolumn{4}{|c|}{ 验证期 (2008 年 1 月 1 日- 12 月 31 日) } \\
\hline & 绝对误差 & 均方根误差 & $\begin{array}{l}\text { 相对均方 } \\
\text { 根误差/\% }\end{array}$ & $\begin{array}{l}\text { Nash 有 } \\
\text { 效系数 }\end{array}$ & 绝对误差 & 均方根误差 & $\begin{array}{l}\text { 相对均方 } \\
\text { 根误差/\% }\end{array}$ & $\begin{array}{l}\text { Nash 有 } \\
\text { 效系数 }\end{array}$ \\
\hline 屏峰水位 & $0.229 \mathrm{~m}$ & $0.271 \mathrm{~m}$ & 2.431 & 0.993 & $0.191 \mathrm{~m}$ & $0.275 \mathrm{~m}$ & 2.675 & 0.993 \\
\hline 星子水位 & $0.247 \mathrm{~m}$ & $0.311 \mathrm{~m}$ & 2.788 & 0.990 & $0.256 \mathrm{~m}$ & $0.353 \mathrm{~m}$ & 3.433 & 0.988 \\
\hline 都昌水位 & $0.186 \mathrm{~m}$ & $0.236 \mathrm{~m}$ & 2.294 & 0.994 & $0.237 \mathrm{~m}$ & $0.335 \mathrm{~m}$ & 3.569 & 0.986 \\
\hline 棠荫水位 & $0.456 \mathrm{~m}$ & $0.558 \mathrm{~m}$ & 6.507 & 0.934 & $0.389 \mathrm{~m}$ & $0.505 \mathrm{~m}$ & 6.588 & 0.937 \\
\hline 湖口泄量 & $654.9 \mathrm{~m}^{3} / \mathrm{s}$ & $654.9 \mathrm{~m}^{3} / \mathrm{s}$ & 4.688 & 0.940 & $520.3 \mathrm{~m}^{3} / \mathrm{s}$ & $810.4 \mathrm{~m}^{3} / \mathrm{s}$ & 4.801 & 0.927 \\
\hline
\end{tabular}

在模拟区域内选择 4 个水位站点, 即屏峰、星子、都昌、棠荫, 同时选择湖口水文站的泄量测量值分别与 模拟数据进行对比分析. 在验证期,水位误差分析结果 (表 1 ) 表明,位于北部人江水道的屏峰站和星子站的 误差较小,湖区棠荫站误差较大, Nash 有效系数在 $0.937 \sim 0.993$ 之间. 从时间段来看(图 2a、b、c、d), 水位 模拟在枯水期时湖区的误差较大, 原因是枯水期鄱阳湖处于河相,对地形的精度要求较高. 王鹏等 ${ }^{[5]}$ 同样 利用 EFDC 发现, 水位率定结果的 Nash 系数在 $0.905 \sim 0.991$ 之间 (时间是 2001 年), 表明其模拟精度与 本文相当. 湖口泄量 (表 1, 图 2e) 的模拟相对均方根误差为 $4.801 \%$, Nash 有效系数为 $0.927\left(\mathrm{Li}^{\text {等 }}{ }^{[12]}\right.$ 利 用 MIKE 21 的湖口流量模拟结果的相对误差为 $13.7 \%$, Nash 有效系数为 0.87 ), 模拟误差来源有: (1) 地 下水不能准确考虑; (2) 周边分蓄洪区因独立于鄱阳湖自由水面,其与湖区的水量交换无法考虑. 本文的 验证结果显示模拟误差在可接受范围内, 表明建立的鄱阳湖 EFDC 水动力模型能较好地模拟鄱阳湖的水 位和泄量变化.

\section{2 结果与讨论}

\section{1 鄱阳湖水动力过程及倒灌现象验证}

图 3 给出了 2008 年鄱阳湖的“五河” 来流流量和湖口泄量,下面依此分析鄱阳湖水位变化的特点和产 生原因. 可以把 2008 年鄱阳湖水动力过程分为 5 个阶段:第(1)阶段是鄱阳湖的枯水期,水位较低; 第(2)阶段 是涨水期,水位随“五河”流量的增加而上升,来流量和泄量基本相等;第(3)阶段是洪水期或主汛期,湖区水 位在较大洪流作用下快速升到第 1 个峰值; 第(4)阶段是顶托期,受湖口长江水位的顶托作用,湖区继续维持 较高水位, 并发生倒灌现象 (泄量为负值表示长江水从湖口进人鄱阳湖, 即发生倒灌), 在倒灌流量补充下, 湖区水位达到新的峰值; 第(5)阶段是消退期, 泄量增加, 水位消退. 因鄱阳湖只有一条连通长江的出湖口, 所以其水位受湖口长江水位控制, 故长江对鄱阳湖湖域的变化也有控制作用, 具体是: 鄱阳湖水位的上涨主 要受 “五河” 流量的制约, 而丰水期的持续时间和水位消退的快慢主要受湖口长江顶托作用和江水倒灌的制 约 ${ }^{[3,9]}$. 从图 3 可知, 2008 年共发生 4 次长江水倒灌进人鄱阳湖的现象. 


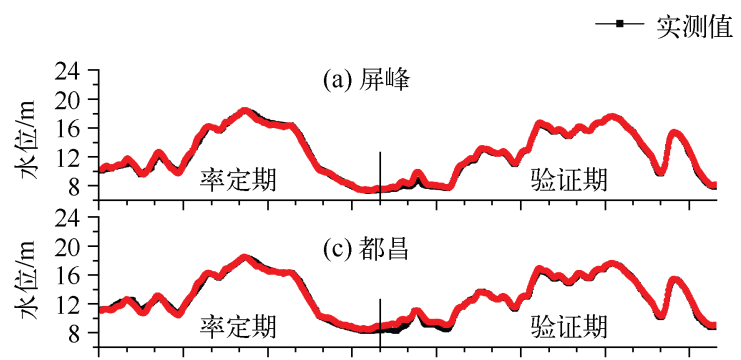

$$
\rightarrow \text { 模拟值 }
$$
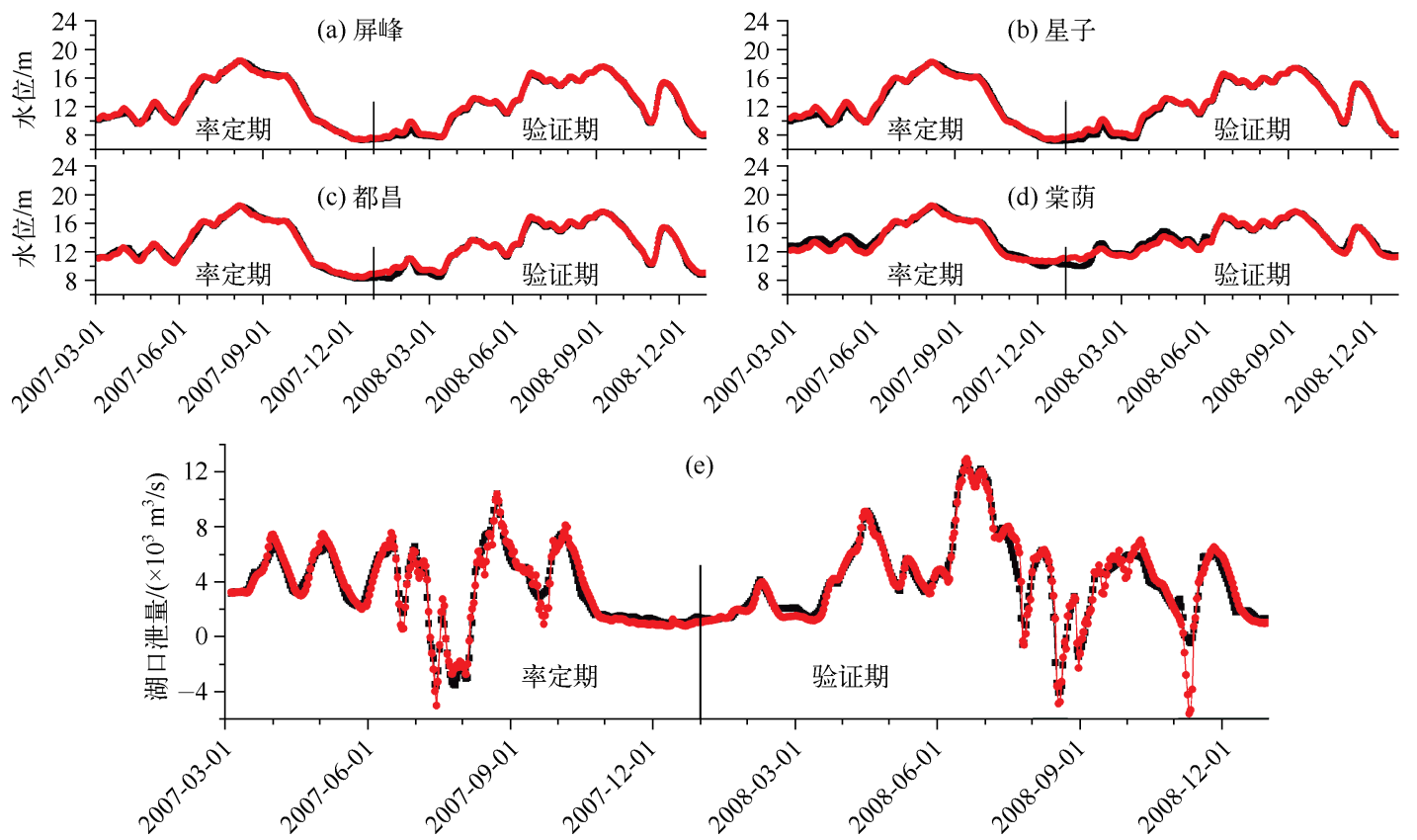

图 2 参数率定期和验证期水文站水位和湖口水文站泄量的测量值与模拟值对比

Fig. 2 Comparison of observed and simulated lake water levels and lake outflow discharges at

Hukou gauging station in parameter calibration period and model validation period

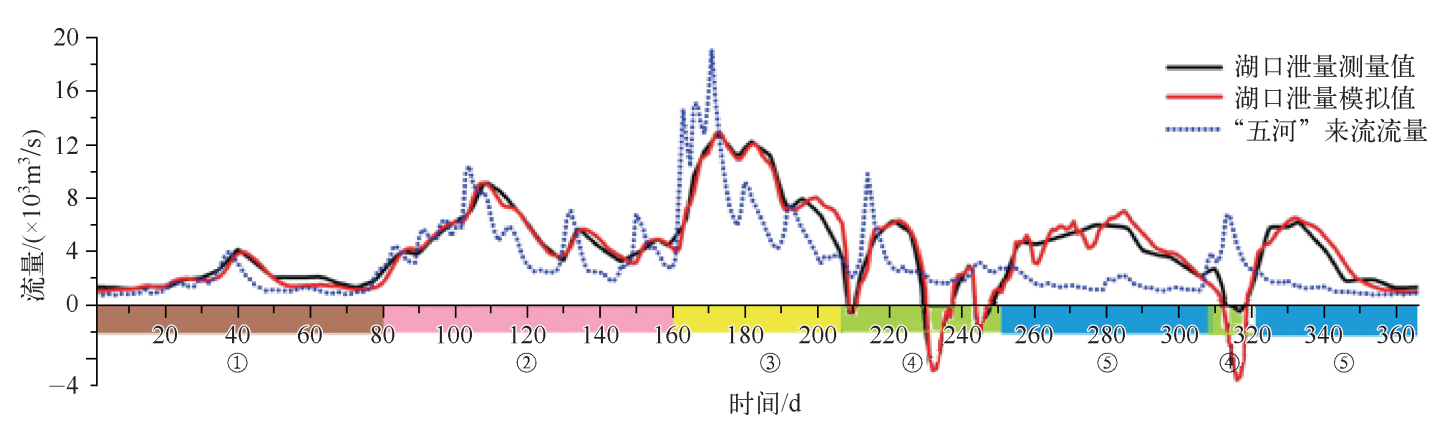

图 32008 年“五河”来流流量和湖口泄量

Fig. 3 “The Five Rivers” inflow volume and Hukou's outflow volume in 2008

表 2 长江倒灌实测结果和模拟结果对比分析

Tab. 2 Comparative analysis of observed and simulated reverse flow from Yangtze River

\begin{tabular}{|c|c|c|c|c|c|c|c|c|}
\hline & \multicolumn{3}{|c|}{ 率定期(2007 年) } & \multicolumn{5}{|c|}{ 验证期(2008 年) } \\
\hline & 第 1 次 & 第 2 次 & 合计 & 第 1 次 & 第 2 次 & 第 3 次 & 第 4 次 & 合计 \\
\hline 实测倒灌发生日期 (月/日) & $7 / 11-7 / 17$ & $7 / 21-8 / 6$ & $24 \mathrm{~d}$ & $7 / 26-7 / 27$ & $8 / 16-8 / 23$ & $8 / 30-9 / 3$ & $11 / 8-11 / 12$ & $20 \mathrm{~d}$ \\
\hline 模拟倒灌发生日期(月/日) & $7 / 11-7 / 17$ & $7 / 21-8 / 5$ & $23 \mathrm{~d}$ & $7 / 27-7 / 28$ & $8 / 17-8 / 23$ & $8 / 30-9 / 2$ & $11 / 7-11 / 12$ & $19 \mathrm{~d}$ \\
\hline 实测倒灌水量 $/\left(\times 10^{8} \mathrm{~m}^{3}\right)$ & 11.3 & 33.9 & 45.2 & 0.91 & 17.0 & 3.9 & 0.88 & 22.7 \\
\hline 模拟倒灌水量 $/\left(\times 10^{8} \mathrm{~m}^{3}\right)$ & 14.3 & 25.9 & 40.2 & 0.79 & 16.7 & 3.4 & 19.80 & 40.8 \\
\hline
\end{tabular}

鄱阳湖倒灌主要发生在夏、秋季丰水期,数值模拟结果和实测结果在倒灌发生时间点及持续时间上都 
相当吻合, 且较精确地模拟了倒灌水量 (表 2). 在验证期 (2008 年), 前 3 次倒灌的模拟结果与实测结果拟合 较好,但是第 4 次误差较大,模拟值为全年最大一次倒灌,但观测结果为全年最小一次倒灌. 综合水位、流 量、容积等模拟数据, 在第 4 次倒灌 (11月 7 日- 12 日) 时间范围内, 湖区水位快速升高 $2.74 \mathrm{~m}$, 鄱阳湖湖体 增加 $55.5 \times 10^{8} \mathrm{~m}^{3}$, 期间 “五河” 来流为 $33.3 \times 10^{8} \mathrm{~m}^{3}$ (包含区间流), 且气象数据显示湖域无降雨, 所以可以 理解模拟得到的倒灌流量为 $19.8 \times 10^{8} \mathrm{~m}^{3}$ 的原因. 2008 年第 4 次倒灌流量模拟值和实测值相差较大的可能 原因分析如下.

首先,有模拟精度上的原因:第 4 次倒灌期间湖口水位变化范围为 $11.7 \sim 15.1 \mathrm{~m}$, 根据方春明等 ${ }^{[7]}$ 的结 果, 鄱阳湖从 $14 \mathrm{~m}$ 水位逐渐由河相改变为湖相, $15 \mathrm{~m}$ 以上为湖相,所以在此期间鄱阳湖开始是河相, 然后逐 步转变为湖相, 在最后的时候才呈现湖相. 由于本文地形数据为 1998 年测量, 无法准确反映 2008 年的河道 地形, 从而影响河相的模拟精度. 其次,有实际测量方面的原因: (1) 在倒灌期间, 流速动态性较强,湖流形 态产生较大变化且较复杂, 湖水含沙量也会出现较大改变; (2) 在倒灌初期湖流开始逆向, 湖湾处由于逆向 人流会引起环流,使湖流顺逆不定（图 4); (3) 在垂向上,流速首先发生逆向的是表层水体,然后是底层.上 述原因都会对流量的测定精度带来影响 ${ }^{[13]}$. $\mathrm{Li}^{\text {等 }}{ }^{[12]}$ 利用 MIKE 21 的模拟结果显示, 在其中两次倒灌期间, 模拟值和测量值同样存在较大偏差.

\section{2 倒灌发生条件}

在 2008 年 4 次发生倒灌时间段内,鄱阳湖水位升高较大(利用表 2 的时间区间,确定湖区平均水位改变 幅度): 第 1 次倒灌湖区水位上升幅度为 $0.54 \mathrm{~m}$ (从 $15.22 \mathrm{~m}$ 升至 $15.76 \mathrm{~m}$ ); 第 2 次倒灌湖区水位上升幅度 为 $0.88 \mathrm{~m}$ (从 $15.83 \mathrm{~m}$ 升至 $16.71 \mathrm{~m}$ ); 第 3 次倒灌在时间上与第 2 次倒灌非常接近, 只有 $7 \mathrm{~d}$ 的时间间隔,湖 区水位上升幅度为 $0.26 \mathrm{~m}$ (从 $17.03 \mathrm{~m}$ 升至 $17.29 \mathrm{~m}$ ), 紧接着达到全年最高水位; 第 4 次倒灌发生在鄱阳湖 水位消退至较低值期间, 模拟倒灌量为全年最大,水位上升幅度为 $2.74 \mathrm{~m}$ (从 $12.43 \mathrm{~m}$ 升至 $15.17 \mathrm{~m}$ ). 倒灌 发生时,前 3 次都发生在“五河” 来流较小的时候(图 3), 但第 4 次倒灌发生时, “五河”已经涨水, 且在倒灌 期间“五河”出现 1 次小洪峰,所以虽然倒灌和“五河”来流有关联,但不是来流流量小就是倒灌发生的前提. 从倒灌发生时的水位特点看, 前 3 次都较高, 鄱阳湖处于湖相, 第 4 次鄱阳湖水位较低, 鄱阳湖处于河相, 所 以倒灌既可能发生在丰水期,也有可能发生在枯水期. 接下来, 鄱阳湖的一个关键问题是: 在什么条件下倒 灌会发生?

对于上面的问题,方春明等 ${ }^{[7]}$ 分析认为, 倒灌是江湖作用的直接体现, 长江在湖口的顶托作用强于鄱阳 湖盆地作用是倒灌发生的条件,具体可以描述为长江九江站流量日涨幅超过了鄱阳湖湖口前一天的流量. 在倒灌期,必然会使湖区较大范围湖流逆向,由图 5 可知,鄱阳湖湖区水面倾斜方向必然也会发生反向,即 湖口水位大于湖区水位. 鄱阳湖湖口与长江相连, 方春明等 ${ }^{[7]}$ 的分析表明: 湖口水位与长江干流流量相关性 较好, 而与湖口流量之间只是部分相关, 相关关系散乱. 胡茂林等 ${ }^{[20]}$ 依据 2007-2008 年湖口、长江 (九江 站) 的逐日水位数据, 分析出湖口水位与长江水位呈直线正相关. 基于鄱阳湖水位受 “五河” 来流和湖口长江 水位同时影响的特点, 倒灌发生的临界点可以认为是湖口的泄量为零的时候, 此时湖泊的来流必然会使湖 区水位升高 (设为 $\mathrm{d} H$, 理解为 “五河”盆地作用产生的水位变化), 如果要让泄量为零继续, 就要求湖口水位 也要同时升高 (设为 $\mathrm{d} H^{*}$, 湖口水位受长江控制, 理解为江湖作用产生的水位变化), 且满足 $\mathrm{d} H^{*}=\mathrm{d} H$; 易 知, 当 $\mathrm{d} H^{*}>\mathrm{d} H$ 时, 就会打破临界状态, 出现如图 5 所示的水位梯度分布, 从而发生江水倒灌现象. 同时, $\mathrm{d} H^{*}>\mathrm{d} H$ 体现的是长江顶托作用大于 “五河” 作用, 而这就是倒灌发生的条件 ${ }^{[7,10]}$. 在倒灌发生临界点,假设 已知湖口水位 $H^{*}(t)$ (通过测量, 或者通过长江干流流量都可以得到), 使 $\mathrm{d} H=\mathrm{d} H^{*}$, 则临界来流流量 $\left(Q_{\mathrm{L}}\right)$ 为:

$$
Q_{\mathrm{L}}=\frac{\mathrm{d} H^{*}(t)}{\mathrm{d} t} \cdot \frac{\mathrm{d} V}{\mathrm{~d} H}=\frac{\mathrm{d} V}{\mathrm{~d} t}=k \cdot k^{\prime}
$$

式中, $V$ 为湖区水体体积, $\frac{\mathrm{d} H^{*}(t)}{\mathrm{d} t}=k$ 表示湖口水位变化率, $\frac{\mathrm{d} V}{\mathrm{~d} H}=k^{\prime}$ 代表在水位 $H$ 时的湖区水面面积. 当实际 来流 $Q_{\mathrm{r}}<Q_{\mathrm{L}}$ 时 (即满足 $\mathrm{d} H^{*}>\mathrm{d} H$ 条件), 倒灌发生, 反之则不会发生, 所以倒灌发生判别条件可以表示为: 


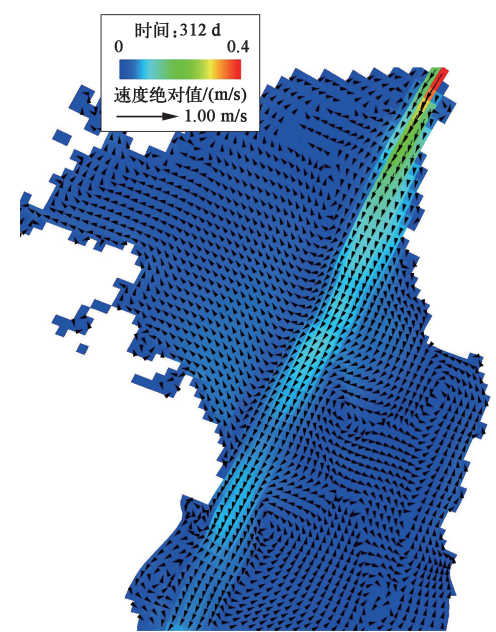

a. 湖口倒灌发生初期

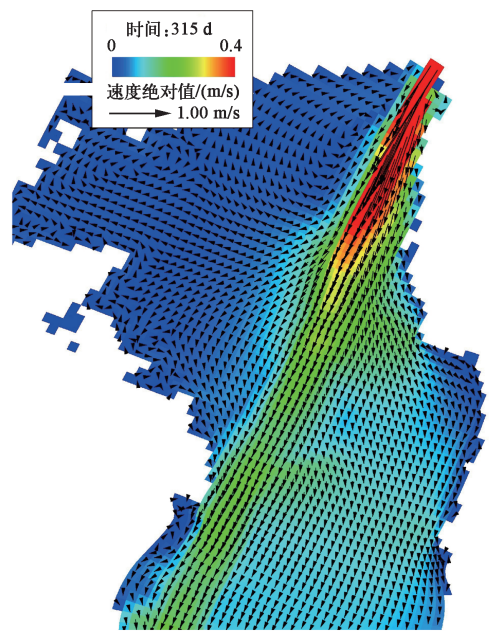

b. 湖口倒灌发生中期

图 4 倒灌期鄱阳湖湖口流场

Fig. 4 Flow fields of Hukou in Lake Poyang during reverse flow period

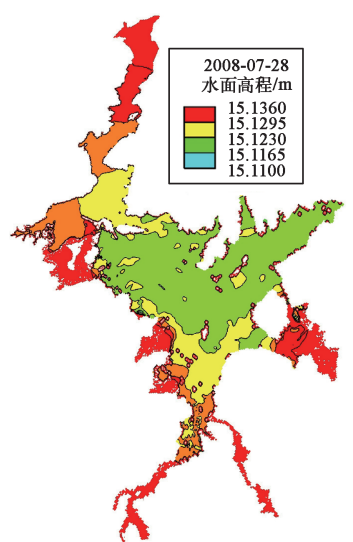

a. 第1次

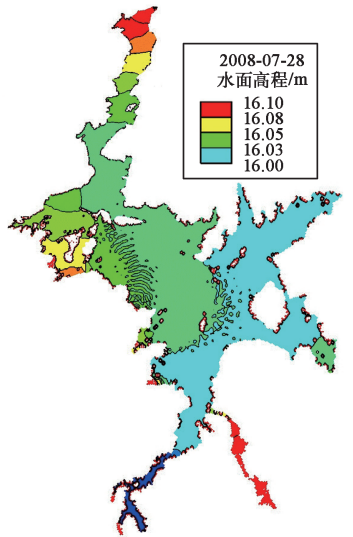

b. 第2次

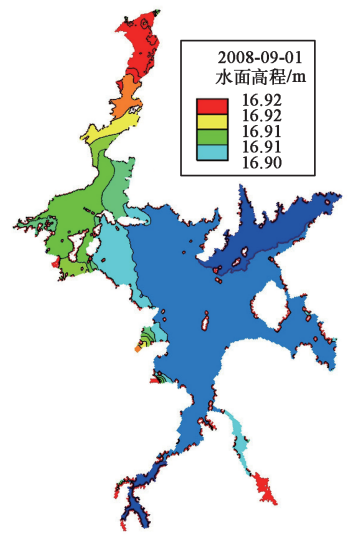

c. 第3次

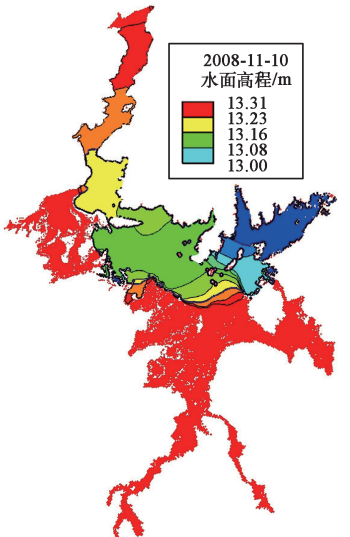

d. 第4次

图 52008 年鄱阳湖倒灌期湖区水位特点

Fig. 5 Lake Poyang water level features during reverse flow period in 2008

$$
Q_{\mathrm{r}}<Q_{\mathrm{L}}
$$

由于区间流、降雨、地下水和“五河” 流量测量站点并不在人湖口等原因, 实际来流并不等于 “五河” 总 来流. 基于水量平衡, $Q_{\mathrm{r}}$ 可由 “五河”总来流 $\times 1.258$ 估算得到. 图 6 得到的鄱阳湖水体体积、面积与水位的 关系是在鄱阳湖数值模型、假设水位相同的基础上得到的, 并不代表鄱阳湖实际情况, 尤其在 $H<14 \mathrm{~m}$ 河相 时, 湖区水力梯度较大 (方春明等 ${ }^{[7]}$ 分析表明湖区各站水位与湖口水位都成一定的绳套曲线). 但是在湖相 时由于湖区水位平均, 图 6 可以较好地反映实际情况, 所以利用此图获得湖面面积 $k^{\prime}$ 可以代到式 (1) 中 计算 $Q_{\mathrm{L}}$ : 首先, 实际大部分倒灌发生在水位 $14 \mathrm{~m}$ 以上; 其次, 对在水位 $14 \mathrm{~m}$ 以下发生的倒灌, 也会当倒灌 持续一段时间后, 水位迅速升高到 $14 \mathrm{~m}$ 以上. 图 6 中的湖面面积曲线,利用 6 次多项式拟合得到的表达 式为: 


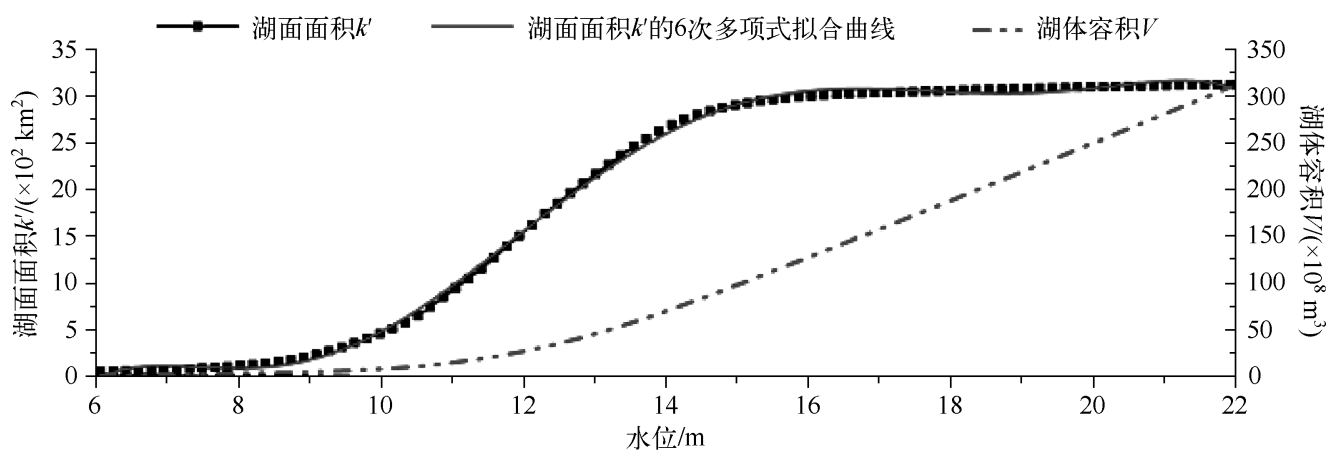

图 6 鄱阳湖湖体体积、湖面面积与水位的关系

Fig. 6 Relationships between water volume, area and water level of Lake Poyang

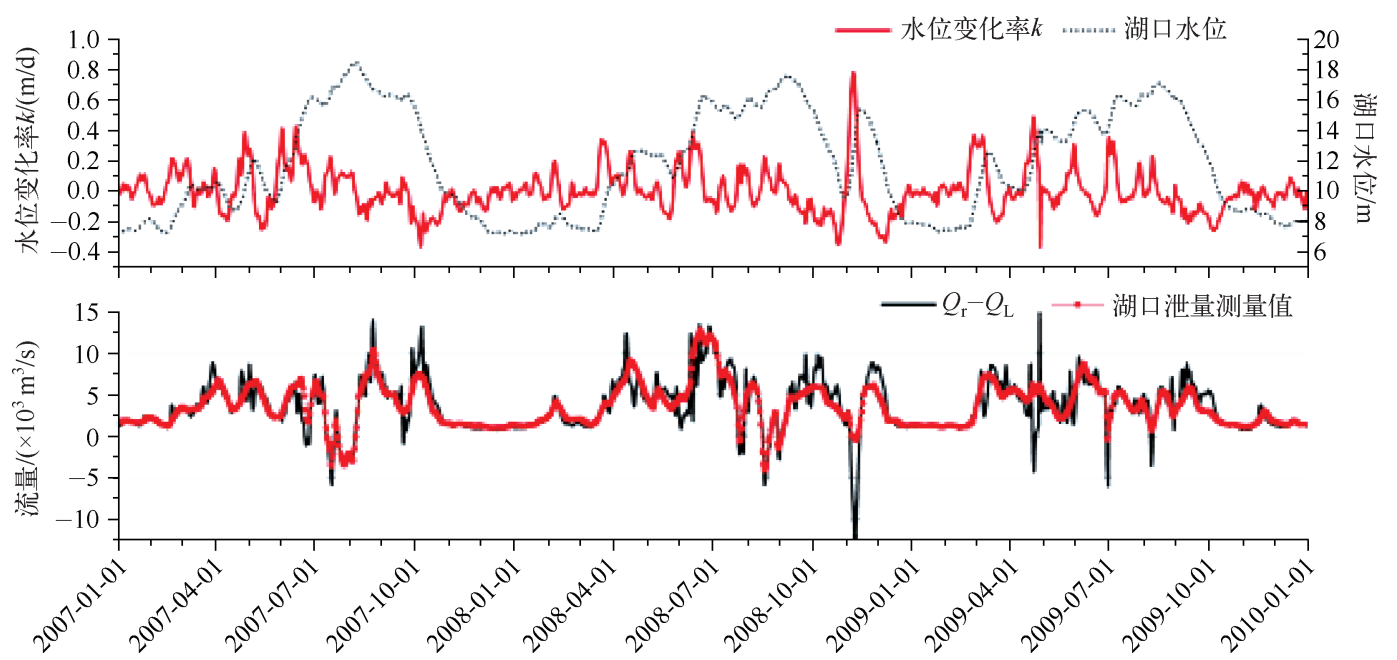

图 7 鄱阳湖湖口长江水倒灌条件

Fig. 7 The Yangtze River reverse conditions on Hukou of Lake Poyang

表 3 江水倒灌判别条件验证

Tab. 3 The validation of reverse flow from Yangtze River conditions

\begin{tabular}{|c|c|c|c|c|c|c|c|c|c|c|c|c|c|}
\hline & \multicolumn{5}{|c|}{2007 年 } & \multicolumn{5}{|c|}{2008 年 } & \multicolumn{3}{|c|}{2009 年 } \\
\hline & 第 1 次 & 第 2 次 & 第 3 次 & 第 4 次 & 合计 & 第 1 次 & 第 2 次 & 第 3 次 & 第 4 次 & 合计 & 第 1 次 & 第 2 次 & 合计 \\
\hline $\begin{array}{l}\text { 实测发生日期 } \\
\text { (月/日) }\end{array}$ & 无 & $\begin{array}{l}7 / 11- \\
7 / 17\end{array}$ & $\begin{array}{l}7 / 21- \\
8 / 6\end{array}$ & 无 & $24 \mathrm{~d}$ & $\begin{array}{l}7 / 26- \\
7 / 27\end{array}$ & $\begin{array}{l}8 / 16- \\
8 / 23\end{array}$ & $\begin{array}{l}8 / 30- \\
9 / 3\end{array}$ & $\begin{array}{l}11 / 8- \\
11 / 12\end{array}$ & $20 \mathrm{~d}$ & $7 / 1$ & 无 & $1 \mathrm{~d}$ \\
\hline $\begin{array}{l}\text { 预测发生日期 } \\
\text { (月/日) }\end{array}$ & $\begin{array}{l}6 / 21- \\
6 / 25\end{array}$ & $\begin{array}{l}7 / 12- \\
7 / 18\end{array}$ & $\begin{array}{l}7 / 22- \\
8 / 6\end{array}$ & $9 / 20$ & $29 \mathrm{~d}$ & $\begin{array}{l}7 / 25- \\
7 / 30\end{array}$ & $\begin{array}{l}8 / 17- \\
8 / 23\end{array}$ & $\begin{array}{l}8 / 31- \\
9 / 2\end{array}$ & $\begin{array}{l}11 / 6- \\
11 / 14\end{array}$ & $24 \mathrm{~d}$ & $\begin{array}{l}6 / 30- \\
7 / 1\end{array}$ & $\begin{array}{l}8 / 10- \\
8 / 11\end{array}$ & $4 \mathrm{~d}$ \\
\hline $\begin{array}{l}\text { 实测倒灌 水量/ } \\
\left(\times 10^{8} \mathrm{~m}^{3}\right)\end{array}$ & 0 & 11.3 & 33.9 & 0 & 45.2 & 0.91 & 17.0 & 3.9 & 0.88 & 22.7 & 0.3 & 0 & 0.3 \\
\hline $\begin{array}{l}\text { 预估倒灌水量/ } \\
\left(\times 10^{8} \mathrm{~m}^{3}\right)\end{array}$ & 2.69 & 18.28 & 31.6 & 0.75 & 53.3 & 6.14 & 20.7 & 5.34 & 53.4 & 85.6 & 8.08 & 4.79 & 12.9 \\
\hline
\end{tabular}

基于提出的倒灌判定条件, 选择 2007-2009 年来验证(图 7). 倒灌的整个判定过程为: 根据测量的湖口 水位 (图 7a 黑点线)求出水位变化率 $k$ (图 7a 红线); 由式(3) 计算得到 $k^{\prime}$; 利用式 $(1)$ 就可以计算出 $Q_{\mathrm{L}}$; 利 
用 $Q_{\mathrm{r}}-Q_{\mathrm{L}}$ 得到图 7b 黑线表示的流量差, 当其为负值则表示倒灌发生. 同时把该流量差与湖口泄量测量值 (图 7b 红点线) 对比发现, 二者具有较好的相关关系, 这是因为临界来流本质上也可以理解为由于水位变化 产生的净流量, 所以实际来流 - 净流量可以反映需泄出的流量. 江水倒灌判别条件验证 (表 3) 结果表明: (1) 2007 年预测到 4 次倒灌, 实际只发生 2 次,但通过图 7 可知,在预测的第 1 次倒灌时期,湖区水位快速 升高, 实测泄量较小, 反映出此时期长江对鄱阳湖具有较强的顶托作用, 是倒灌发生的临界状态, 预测的第 4 次也有类似状况 (且时间只有 $1 \mathrm{~d}$ ), 同时较准确地预测了实际发生的 2 次倒灌, 且预估的倒灌流量与真实流 量相差不大; (2) 准确地预测了 2008 年的 4 次倒灌现象, 其中第 4 次预估的倒灌流量相差较大, 这与数值模 拟的结果类似; (3) 2009 年出现 3 次负值,但在 5 月份出现负值时水位在 $14 \mathrm{~m}$ 以下,基于实际水力梯度较 大的原因可以认为不能预测倒灌的发生. 总的来说, 实际发生的倒灌基本能较好的预测, 同时在 3 年内共预 测到有 3 次并没有发生的倒灌, 也是具有倒灌流量较小且时间持续时间短的特点, 且实际也是长江顶托作 用较强时期. 综上, 本文通过利用湖口水位 “五河” 来流以及鄱阳湖水体体积与水位关系等基本信息, 确定 了倒灌发生的判别条件,为预测及预估倒灌及其流量提供了新的有效方法.

\section{3 倒灌水体占据的面积和倒灌期湖流流向}

倒灌水体进入湖区, 会占据一定的面积, 其面积大小与总倒灌水体的量有关. 通过模拟染色剂可以确定 倒灌面积, 具体方法是在赣江中持续释放浓度为 $1 \mathrm{mg} / \mathrm{L}$ 的染色剂, 对赣江水体染色, 由于倒灌水体来自湖 口, 无染色剂, 所以倒灌水体的染色剂浓度为零. 如图 8a,b 和图 8c, d 是 2008 年第 $2 、 4$ 次倒灌发生前后染色 剂的分布, 北部蓝色区域表示长江倒灌人流占据的区域. 鄱阳湖 2008 年 4 次倒灌人流扩散占据的面积依次为 $29.01 、 199.34 、 107.47$ 和 $373.92 \mathrm{~km}^{2}$ (其对应的倒灌流量见表 2), 分别占湖区总面积的 $0.97 \% 、 6.6 \% 、 3.5 \%$ 和 $12.6 \%$.

由图 8 可知, 在正常情况下, 赣江来水流经湖区西南的赣江三角洲平原 (面积 $1540 \mathrm{~km}^{2}$, 是我国最大的 湖泊三角洲), 然后在中央人江水道处与抚河、信江、饶河等来水相汇, 最后流过狭长的北部人江水道经湖口 流人长江, 并不会因自西向东倾斜的横坡降而穿过中央水道进人湖区的东北湖湾. 但是, 当倒灌发生后, 由 于湖流逆向, 水体向南退却, 倒灌发生前原来占据狭长人江水道区域的水体逆向流人东北湖湾, 使来自赣江 的水体以此机会进入该区域. 图 5 中倒灌期水位倾斜方向, 同样反映了倒灌期湖流的流向: 在不同的倒灌流 量、水位、及“五河” 来流条件下, 倒灌的湖流流向也呈现不同的特点. 综上, 倒灌使江水进人湖区, 同时对污 染物、营养物质和水体中的藻类等物质的输运和分布会产生新的影响, 在鄱阳湖水环境模拟中, 倒灌现象是 绝对不能忽视的一个因素.

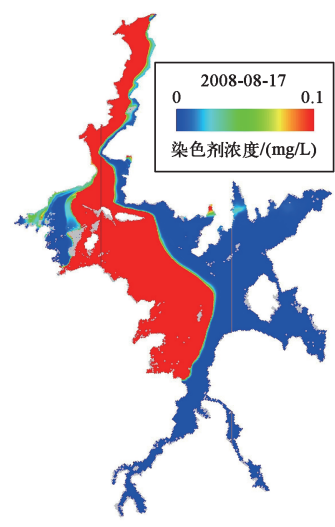

a. 2008年第2次倒灌前

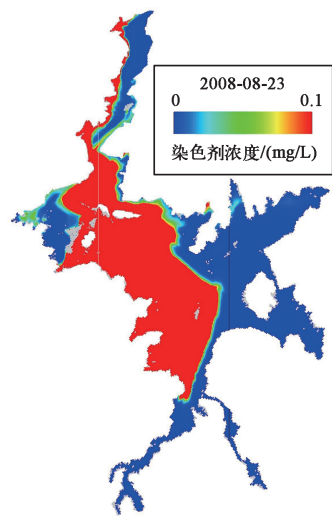

b. 2008年第2次倒灌后

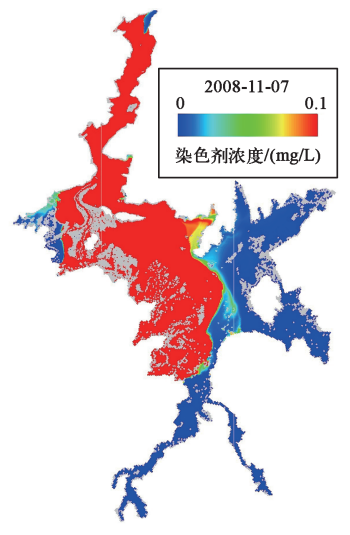

c. 2008年第4次倒灌前

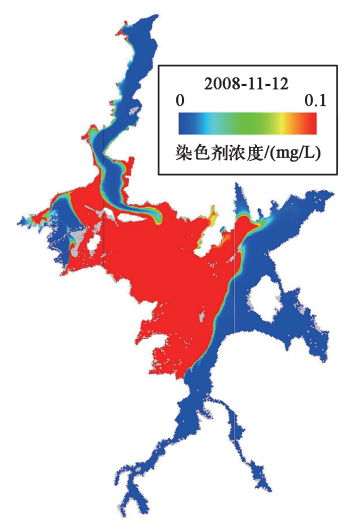

d. 2008年第4次倒灌后

图 8 倒灌水体面积

Fig. 8 The area of reverse flow water

\section{4 顶托及倒灌作用对水龄的影响}

为研究长江的顶托及倒灌作用对鄱阳湖的影响, 本文模拟鄱阳湖水体 2008 年的水龄. 水龄表示湖水从 
人口 (或者说外界) 进人湖区后停留的时间, 是研究湖泊水动力的一个重要参数. 为了进行对比分析, 再引人 另外一个表征湖泊物理特征的重要参数,即水力停留时间.

通过出流完全排空湖水的平均时间称为水力停留时间, 被定义为湖水的体积与流出速率的比值 ${ }^{[14]}$ :

$$
\Gamma=V / Q
$$

式中, $\Gamma$ 为水力停留时间, $V$ 为湖体水体体积, $Q$ 为湖口流出速率. 水力停留时间对湖泊的富营养化有显著影 响. 水力停留时间短会缩短生物生长的时间, 从而减少生物量的累积; 水力停留长则有利于营养物质的再循 环和保持,会在湖水中停留较长的时间, 藻类也会有较长的时间生长.

模拟获得的鄱阳湖湖口处水体的水龄时间序列见图 9, 根据水龄的含义, 该点的水龄等于湖水从人湖到 出湖所经历的时间,其本质与由式 (4) 计算的水力停留时间具有相同的含义和意义. 湖口处水龄在 4 个时 间段为零 (图 9), 且和倒灌发生时间段吻合, 即湖口水龄为零也可以作为倒灌发生的标志, 原因是: 当倒灌发 生时, 湖口处是长江水进入湖区, 即出口变人口, 此时水龄必然为零. 同时, 水力停留时间在顶托倒灌期间, 变得较大或为负值,这是因为泄量极小或为负的缘故. 这种较大或者负值的水力停留时间并不能反映鄱阳 湖水体实际停留情况, 不具有意义,所以在图 9 中纵坐标标值范围选择为 $-10 \sim 70 \mathrm{~d}$.

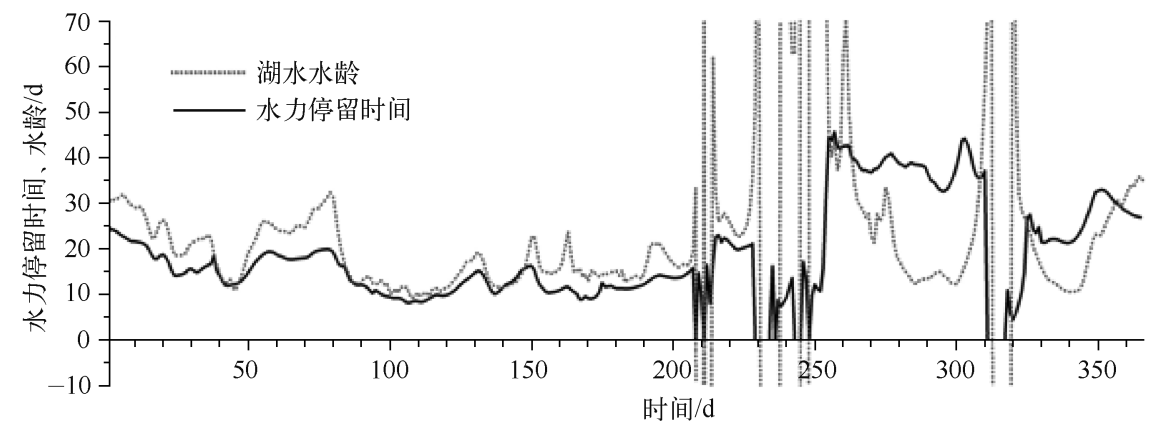

图 92008 年出湖湖水水龄和水力停留时间

Fig. 9 Water age of lake outlet and hydraulic retention time in 2008

2008 年湖口水龄和水力停留时间在大部分时间段一致, 7 月份以前基本在 $10 \sim 30 \mathrm{~d}$ 范围内波动 (图 9), 反映了鄱阳湖作为过水性湖泊水体交换时间短的特点. 但是, 在发生倒灌作用期间及以后, 两者出现较大的 偏差: 首先, 顶托倒灌期, 水力停留时间值很大或为负, 不能反映实际情况从而失效, 而水龄出现零值, 此时湖 区水体的水龄因顶托继续增加; 其次, 当顶托倒灌作用减弱以后 (如第 3 次倒灌发生后的第 $260 \sim 300 \mathrm{~d}$, 以及 第 4 次倒灌发生的第 $320 \mathrm{~d}$ 以后), 由于水力停留时间无法考虑前期顶托及倒灌作用的影响, 相反, 模拟的水 龄则不受限制, 所以出现偏差. 在顶托倒灌作用期间, 由 “五河” 进入湖区的湖水不能顺利泻出, 长期滞留, 水 龄增加, 其效果可由出现偏差情况反映. 如第 $2 、 3$ 次倒灌发生的时间非常接近, 期间只有少量的水泻出, 从 第 $229 \mathrm{~d}$ 顶托作用开始, 到第 $250 \mathrm{~d}$ 结束, 然后湖口泄量大增, 开始泻出的湖水是由倒灌流人的, 直到第 $255 \mathrm{~d}$ 后将是由 “五河” 来水的泻出, 经历的时间是 $26 \mathrm{~d}$ 左右. 在第 $285 \mathrm{~d}$, 湖口水体的水龄为 $38.7 \mathrm{~d}$, 水力停留时间 为 $12.3 \mathrm{~d}$, 两者的差是 $26.4 \mathrm{~d}$, 刚好等于前面的顶托倒灌和倒灌水体泻出时间和. 综合来说, 顶托倒灌作用增 加水体体积, 稀释了湖区水体营养物质的浓度, 但同时也使湖水滞留, 增加湖区水体的水龄: 对靠近北部湖 口处湖体来说, 水龄增加不大, 稀释作用明显, 有利于改善水质; 中央湖区东部湖湾, 其水龄原本较长, 水体 交换慢, 且远离湖口, 水龄的增加将会加大发生富营养化的风险, 模拟显示在第 $300 \mathrm{~d}$ 该区域的水龄达到了 $270 \mathrm{~d}$ 的峰值.

\section{3 结论}

通过利用 EFDC 的水动力模块、染色剂模块和水龄模块, 模拟鄱阳湖的水动力学过程, 并对倒灌期的模 拟结果进行详细的分析, 结果表明: (1) 鄱阳湖在夏、秋季的丰水期会发生倒灌现象, 数值模拟结果精确地 
验证了倒灌的发生和持续时间, 显示倒灌时期湖区水力梯度、湖流逆向的特点; (2) 长江发生倒灌的条件是 实际总来流小于临界来流, 该判定条件准确有效, 为预测倒灌发生及预估其倒灌流量提供了新的有效方法; (3) 鄱阳湖 2008 年 4 次倒灌人流扩散占据的面积依次为 $29.01 、 199.34 、 107.47$ 和 $373.92 \mathrm{~km}^{2}$, 分别占湖区 总面积的 $0.97 \% 、 6.6 \% 、 3.5 \%$ 和 $12.6 \%$; (4) 长江的顶托作用使湖水不能顺利外泄, 增加湖体水龄, 而出湖 水体水龄的增加时间可以由顶托作用时间 + 倒灌水体泻出时间估算.

\section{4 参考文献}

[ 1 ] 《鄱阳湖研究》编委会. 鄱阳湖研究. 上海: 上海科学技术出版社, 1988:18-33.

[2] 叶许春, 李相虎, 张 奇. 长江倒灌鄱阳湖的时序变化特征及其影响因素. 西南大学学报: 自然科学版,2012,34 (11) :69-75.

[ 3 ] 赵修江, 孙志禹, 高 勇. 三峡水库运行对鄱阳湖水位和生态的影响. 三峡论坛,2010,230(5):19-22.

[4]许继军,陈 进. 三峡水库运行对鄱阳湖影响及对策研究. 水利学报,2013,44(7):757-763.

[ 5] 王 鹏, 赖格英, 黄小兰. 鄱阳湖水利枢纽工程对湖泊水位变化影响的模拟. 湖泊科学, 2014,26(1):29-36.

[6] 郭 华,张 奇. 近 50 年来长江与鄱阳湖水文相互作用的变化. 地理学报,2011,66(5):609-618.

[ 7 ] 方春明,曹文洪,毛继新等. 鄱阳湖与长江关系及三峡蓄水的影响. 水利学报,2012,43(2):175-181.

[8] 胡春宏, 阮本清. 鄱阳湖水利枢纽工程的作用及其影响研究. 水利水电技术, 2011,42(1):1-6,20.

[9] 闵 骞. 20 世纪 90 年代鄱阳湖洪水特征的分析. 湖泊科学,2002,14(4) :323-330.

[10] Hu Q, Feng S, Guo H et al. Interactions of the Yangtze River flow and hydrologic processes of the Lake Poyang, China. Journal of Hydrology, 2007,347 (1) : 90-100.

[11] 胡春华. 历史时期鄱阳湖湖口长江倒灌分析. 地理学报, 1999,54(1):79-84.

[12] Li YL, Zhang Q, Yao J et al. Hydrodynamic and hydrological modeling of the Lake Poyang catchment system in China. Journal of Hydrologic Engineering, 2004, 19: 607-616.

[13] 谢 波,田岳明,叶建红等. ADCP 河流流量测验及其误差分析. 水资源研究,2007,28(4) :34-36.

[14] 季振刚. 水动力学和水质一一河流、湖泊及河口数值模拟. 北京: 海洋出版社, 2012:18-33.

[15] Hamrick JM. The environmental fluid dynamics code: Theory and computation. US EPA, Fairfax, VA, 2007:10-15.

[16] 王 翠, 孙英兰, 张学庆. 基于 EFDC 模型的胶州湾三维潮流数值模拟. 中国海洋大学学报,2008,38(5):833-840.

[17] 郝文涁, 唐春燕, 滑 否等. 引江济太调水工程对太湖水动力的调控效果. 河海大学学报: 自然科学版, 2012, 40 (2) : 129-133.

[18 ] Deleersnijder E, Campin JM, Delhez EJM. The concept of age in marine modelling: I. Theory and preliminary model results. Journal of Marine Systems, 2001, 28(3) : 229-267.

[19] 郭 华. 鄱阳湖流域 1955-2002 年径流系数变化趋势及其与气候因子的关系. 湖泊科学, 2007,19(2):27-31.

[20] 胡茂林, 吴志强, 刘引兰. 鄱阳湖湖口水位特性及其对水环境的影响. 水生态学杂志, 2010,3 (1):1-6. 